\title{
Transparency and Catching Up in a Monetary Union
}

\author{
Marcelo Sánchez \\ European Central Bank
}

\begin{abstract}
We report transparency scores and growth indicators for the euro area and various classes of potential euro area candidates. We then study currency union stabilization when monetary policy transparency may be imperfect and supply conditions may be country-specific. Sectoral productivity shocks are found to reduce the effectiveness of the single monetary policy compared to monetary autonomy. For a small open economy, a wider cross-country gap in supply slopes (as induced by larger trade openness differentials) favors currency union participation. Small size hampers monetary union stabilization under supply shocks, but not when output target shocks are misperceived by the public.
\end{abstract}

- JEL Classification : E52, E58, D82, F33, F40

- Key Words: monetary union, transparency, catching up, asymmetric information

\section{Introduction}

There is a large literature on optimal monetary policy in currency unions. This literature assumes that the private sector has full information about the degree of transparency of monetary policy. In practice, however, transparency may be less than perfect and communication may fail to be clear regarding the background information behind policy decisions. For instance, while many central banks adopt a quantitative numeric target, they tend to be much less explicit about output targets. In addition to transparency considerations, relevant to currency union formation are cross-country differences in supply-side characteristics, including the

\footnotetext{
*Corresponding address: Marcelo Sánchez: European Central Bank, Kaiserstr, 29, D-60311, Frankfurt am Main, Germany, Tel: +49 691344 6351, Fax: +49 691344 6353, e-mail: marcelo.sanchez@ecb.int 
event that member states are unequally developed. In this sense, transparency and catching up may be important joint features behind monetary union membership, independently from the connexion between the two. Against this background, this paper presents available data on transparency and growth for the euro area and its potential future member states. In so doing, we document both developments back in 1998 (when the euro was launched) and the current situation characterized by three types of potential euro area economies, namely, EU new member states (NMS), non-euro-area non-NMS EU countries (Denmark, Sweden, UK) and EU accession countries. Of these three subgroups, the second one is the only one not comprising catching-up countries. ${ }^{1}$

Further to this empirical evidence, the bulk of this paper proposes a framework for the decision to join a currency union which allows for both imperfect monetary policy transparency and the catching up process of a small open economy. Specifically, we build on two different literatures. First, our modelling of a currency union between two small open economies is closest to Sánchez(2007a, 2008b). The analysis allows for cross-country divergences in supply-side characteristics such as the slope of the Phillips curve and the nature of both aggregate and sectoral productivity shocks. ${ }^{2}$ This approach is particularly useful for the assessment of catching-up countries' decision whether to join a currency union. For the study of this decision, it is crucial to gauge the role played in catching-up countries' development process by the productivity differential between the tradable and non-tradable sectors, which is often seen as contributing to inflation and real exchange pressures. Second, we embed Geraats'(2007) closed economy analysis of informational imperfections into our framework for monetary union between small open economies. ${ }^{3}$ The private sector is unsure how transparent monetary policy is and the central bank is modelled as stabilizing inflation expectations by delivering both actual and perceived transparency about its inflation and output targets. In addition, the monetary authority is found to more easily reach the inflation target by creating the perception of transparency

\footnotetext{
This study is meant to be of more general relevance. The issues raised by monetary transparency and structural change - including productivity-driven exchange rate developments - are important in other currency union contexts. For studies on currency unions as a prospective policy option for catching up economies in East Asia and Latin America, see e.g. Sánchez(2006) and Edwards(2006), and the references therein. Comprehensive international data and discussions on transparency can be found in the studies mentioned in section II.

${ }^{2}$ Sánchez $(2006,2008$ c) present models of monetary union between a large number of economies.

${ }^{3}$ For the role of informational frictions in small open economies, compare the results in Sanchez(2007b, 2008a).
} 
regarding the latter (e.g., by publishing an explicit numeric target). However, it is desirable to create the perception of ambiguity about the output target, which helps reduce expected inflation volatility. The treatment of informational imperfections pursued here draws on two lines of research. First, monetary uncertainty is modelled as arising from shocks to central bank preferences, as also done by e.g. Sørensen(1991) and Eijffinger et al.(2000), where transparency helps reduce private-sector uncertainty and economic volatility. Second, in contrast to the former approach, the nature of information transmission may imply that transparency could be harmful because it leads to higher volatility in private-sector expectations and raises economic uncertainty (see e.g. Cukierman, 2001, and Hahn, 2006). ${ }^{4}$

The present paper makes use of the notion of optimal transparency employed in the related theoretical literature. Most of the latter has concentrated on so-called political and operational transparency, which correspond to transparency about objectives and transparency about central banks' instrument setting and control errors, respectively. For instance, in Cukierman and Meltzer(1986) the private sector cannot distinguish between the impact of monetary policy control errors and change in central bank preferences (see also Faust and Svensson, 2002). In this context, the optimal degree of transparency is determined by two competing effects. The first such effect relates to transparency having the potential to raise disinflation costs as it makes it easier for the private sector to infer central bank preferences for inflation relative to economic expansion. The second effect in question has to do with how transparency, by revealing more about the intentions of the monetary authority, may lower the latter's ability boost output when it is most desired. Depending on the relative strength of these two forces, the monetary authority may opt for operational procedures that do not minimise control-error variance. The transparency concept used in the present paper draws from this literature, even if many features adopted here (including the catching-up and monetary union considerations) are specific to our set-up. It is worth mentioning that the notion of optimal transparency can be extended to deal with environments where central banks are operationally transparent, with opaqueness instead affecting internal forecasts about the economy. One example of this novel branch of optimal transparency studies is Walsh(2007), who examines the degree to which the central bank should disseminate information among private agents. The author

${ }^{4} \mathrm{We}$ abstract from incentive effects relating to transparency as a discipline device for central banks (Faust and Svensson, 2002) or as a coordination mechanism making public signals more reliable (Morris and Shin, 2002). 
develops a framework where predictable policies are most effective, the preferences of inflation-targeting central banks are known, and the policy instrument (interest rate) is easily observable. In a context where the private sector has diverse information, Walsh(2007) finds that the optimal degree of central bank transparency (relating to the provision of public information by interest rate decisions, or announcements about short-run targets) depends on the accuracy with which the monetary authority forecasts cost and demand disturbances.

Our currency union framework adopts the following other features. First, we distinguish between three types of shocks, namely, common, idiosyncratic or asymmetric. This taxonomy allows us to derive meaningful welfare implications about the decision to join monetary union. Second, we introduce a quantitative measure of stabilization performance by comparing a given country's welfare under a currency union with that resulting from conducting monetary policy at the country level. Finally, we carry out sensitivity analysis with respect to crucial structural parameters, such as the aggregate supply slope, country size, and the preference for price stability. With respect to supply slopes, we allow them to exhibit cross-country differences, which we in part interpret in terms of different degrees of openness to international trade.

Overall, thus, the policy question addressed here is the following. The paper aims at contributing to the literature by investigating the role of catching up and monetary misperceptions in a monetary union context. The formulation of the theoretical model is preceded by an examination of relevant empirical evidence. The welfare implications of the theoretical model are studied in terms of a sensitivity analysis centered around calibrated parameter values. All these steps are carried out in the rest of the paper as follows. Section II presents the evidence for growth indicators and transparency scores in an EMU context. In section III, we set up the basic model, which section IV uses to study optimal monetary policy at the country level. Section V characterizes monetary policy as conducted in a currency union. Section VI describes the welfare analysis identifying the factors that influence monetary union stabilization performance. Section VII concludes.

\section{Transparency and Catching Up in an EMU Context}

We start by presenting key data concerning transparency and growth for the euro area and various classes of potential future euro area countries. In so doing, we document evidence on both the situation at the time of the euro's launch in 1998 
and the present circumstances affecting different prospective euro area candidates. Tables 1 and 2 report growth indicators and transparency scores, respectively. Our growth indicators include real GDP growth, labor productivity growth and total factor productivity (TFP) growth for two periods, namely, 1991-1998 and 19992005. The choice of the years is justified by the German reunification (1991), the launch of the euro (1998) and the availability of the latest data (2005). The exception is the choice of 1993 as the starting date for the first period in the case of EU NMS and EU accession countries, in light of lack of information and some economic instability over 1991-1992. Turning to the transparency indicators in Table 2, we use the three datasets available for our purposes. Fry et al.'s(2000) data measures the quality of 'policy explanations' concerning policy decisions, forecasts and risks to the latter, and published assessments and research. Fry et al.'s(2000) indices are constructed using survey responses from central banks. In contrast, Dincer and Eichengreen's(2007) and Crowe and Meade's(2008) data cover a wider variety of transparency aspects (including so-called political, economic, procedural, policy and operational dimensions) and are derived from information available publicly on central bank's websites and publications. In terms of availability, Fry et al.(2000) only covers year 1998, while Dincer and Eichengreen(2007) (henceforth DE) and Crowe and Meade(2008) (henceforth CM) report data for both 1998 and a recent year (2005 and 2006, respectively). In all cases, a higher value indicates more monetary policy transparency.

Back in 1998, the euro area consisted of 11 countries, those listed in Tables 1 and 2 minus Greece, which adopted the euro only in 2001. For the sake of comparability, we decide to include Greece among euro area countries ever since 1991. For the period 1991-1998, Table 1 shows considerable disparities in growth in real GDP and labor productivity among the twelve older euro area members (including TFP growth for those countries for which data are available). In particular, economies that were catching up during this period (Greece, Ireland, Portugal and Spain) exhibited more dynamism than the average of their later currency union partners. In 1998, Table 2 indicates that there were important differences concerning the degree of monetary policy transparency between the countries in question. Indeed, back then, compared with a constructed average of transparency scores for the euro area, Ireland and Portugal were above and Greece below, while Spain's relative position depends on the source used (above in Fry et al.'s and below in CM). Over the period 1998-2006, the CM indicator shows that the homogenization of transparency across the monetary union implied an 
Table 1. Real Output Growth Indicators for Euro Area's Current and Potential Future Member Countries (Average Annualised Growth Rates)

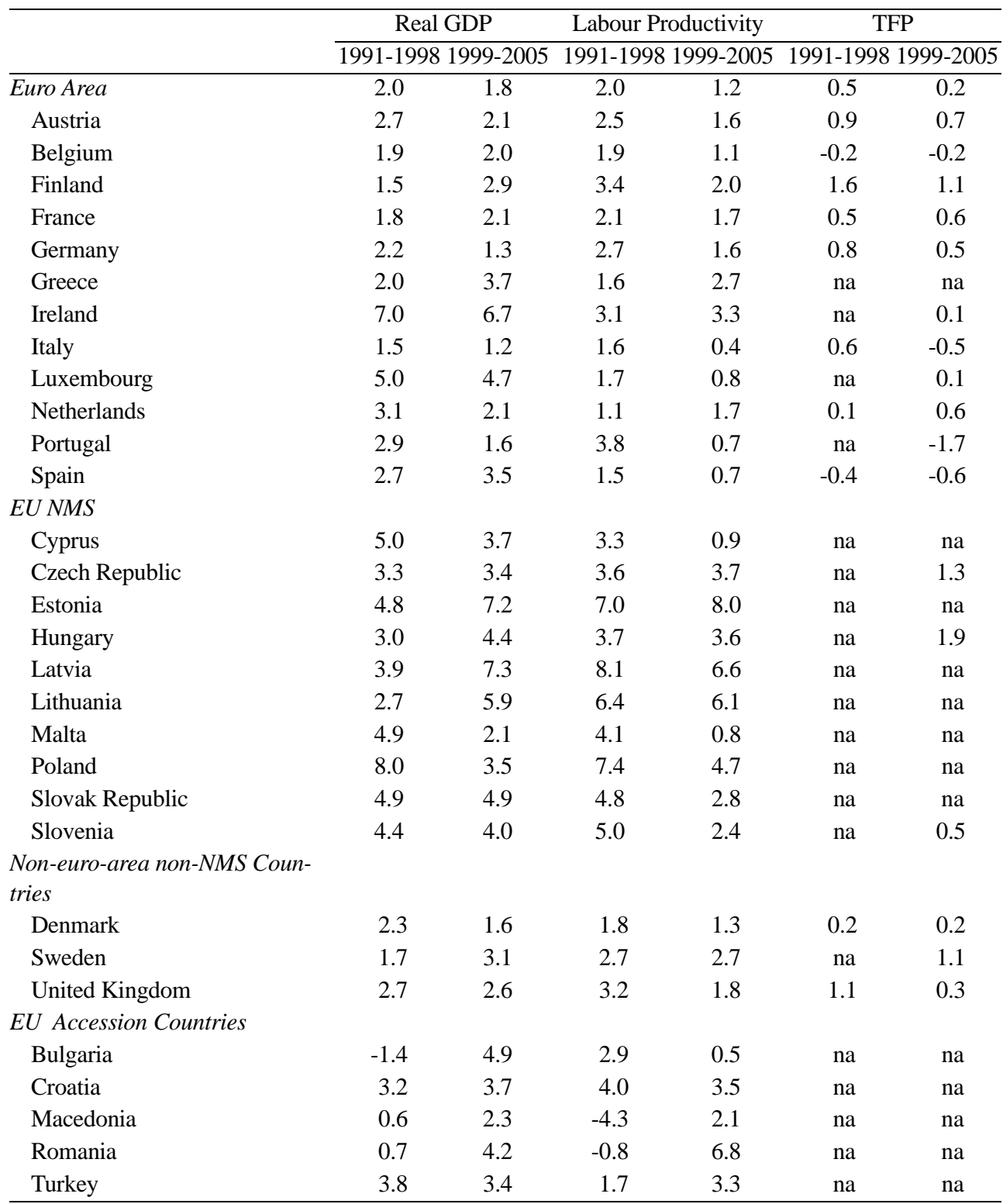

Sources: EU KLEMS except for data for data other than TFP for EU NMS and accession countries (from IMF's International Financial Statistics).

Notes: Euro area's current and potential future member countries are classified according to the information available at the end of the sample period here considered (2005). Following this same criterion, potential future member countries include three categories, namely, EU NMS, non-euro-area non-NMS EU countries and EU accession countries. The euro area aggregate is taken from EU KLEMS and consists of the following countries: Austria, Belgium, Finland, France, Germany, Italy, Netherlands and Spain. TFP stands for total factor productivity growth and is based on gross value added data. Labour productivity is measured as real GDP per hour worked in EU KLEMS and real GDP per person employed in the IMF's International Financial Statistics. For EU NMS and EU accession countries, real GDP and labour productivity are for 19931998 regarding the first period considered. 
Table 2. Transparency Scores for Euro Area's Current and Potential Future Member Countries

\begin{tabular}{|c|c|c|c|c|c|}
\hline & \multicolumn{2}{|c|}{ Crowe-Meade(2008) } & \multicolumn{3}{|c|}{ Dincer-Eichegreen(2007) Fry et al.(2000) } \\
\hline & 1998 & 2006 & 1998 & 2005 & 1998 \\
\hline Euro Area & 0.45 & 0.60 & 8.5 & 10.5 & 0.45 \\
\hline Austria & 0.20 & 0.60 & na & na & 0.27 \\
\hline Belgium & 0.30 & 0.60 & na & na & 0.68 \\
\hline Finland & 0.60 & 0.60 & na & na & 0.74 \\
\hline France & 0.40 & 0.60 & na & na & 0.53 \\
\hline Germany & 0.35 & 0.60 & na & na & 0.70 \\
\hline Greece & 0.40 & 0.60 & na & na & 0.36 \\
\hline Ireland & 0.65 & 0.60 & na & na & 0.78 \\
\hline Italy & 0.60 & 0.60 & na & na & 0.81 \\
\hline Luxembourg & 0.30 & 0.60 & na & na & na \\
\hline Netherlands & 0.70 & 0.60 & na & na & 0.79 \\
\hline Portugal & 0.55 & 0.60 & na & na & 0.78 \\
\hline Spain & 0.35 & 0.60 & na & na & 0.59 \\
\hline$E U N M S$ & 0.51 & na & 4.7 & 7.3 & 0.63 \\
\hline Cyprus & 0.10 & na & 2.5 & 6.5 & 0.48 \\
\hline Czech Republic & 0.80 & 0.70 & 9.0 & 11.5 & 0.86 \\
\hline Estonia & 0.50 & na & 5.0 & 6.0 & 0.71 \\
\hline Hungary & 0.50 & 0.90 & 3.0 & 9.5 & 0.49 \\
\hline Latvia & 0.40 & na & 6.0 & 6.0 & 0.74 \\
\hline Lithuania & 0.60 & na & 4.0 & 4.5 & 0.63 \\
\hline Malta & 0.55 & na & 5.0 & 7.0 & 0.67 \\
\hline Poland & 0.70 & 0.90 & 3.0 & 8.0 & 0.69 \\
\hline Slovak Republic & 0.50 & 0.70 & 4.0 & 6.0 & 0.49 \\
\hline Slovenia & 0.45 & 0.40 & 5.0 & 7.5 & 0.54 \\
\hline $\begin{array}{l}\text { Non-euro area non-NMS coun- } \\
\text { tries }\end{array}$ & na & na & 8.3 & 10.3 & na \\
\hline Denmark & na & na & 5.0 & 6.0 & na \\
\hline Sweden & 0.90 & 0.90 & 9.0 & 13.0 & 0.95 \\
\hline United Kingdom & 0.90 & 1.00 & 11.0 & 12.0 & 0.94 \\
\hline EU Accession Countries & 0.38 & na & na & na & 0.38 \\
\hline Bulgaria & 0.30 & na & 4.5 & 6.5 & 0.46 \\
\hline Croatia & 0.40 & na & 1.5 & 2.5 & 0.42 \\
\hline Macedonia & 0.45 & na & na & na & 0.56 \\
\hline Romania & 0.45 & na & 1.5 & 6.5 & 0.60 \\
\hline Turkey & 0.30 & 0.80 & 3.0 & 8.5 & 0.24 \\
\hline
\end{tabular}

Notes: Euro area's current and potential future member countries are classified according to the information available at end of the sample period here considered (2006). Following this same criterion, potential future member countries are further subclassified into three categories, namely, EU NMS, non-euro-area non-NMS EU countries and EU accession countries. We calculate means for the different groupings as unweighted averages whenever data for all countries are available. The exception to this is the euro area for the Fry et al.(2000) database, in which case data for Luxemboug are missing. 
upgrading for some countries and a deterioration in others. As with the DE measure, these scores reveal that the current state of affairs marks an amelioration in monetary policy transparency for euro area countries as a whole. An improvement is also found for the euro area transparency index by Eijffinger and Geraats(2006) between 1999 and 2002. With regard to growth-related intra-euroarea differences, Table 1 reports that, since the launch of the euro, they have persisted and even increased somewhat judging from the rise in the standard deviation for labor productivity and especially TFP growth since euro adoption.

Recently, the euro area has expanded to include Slovenia in 2007, and Cyprus and Malta in 2008, while the Slovak Republic is expected to adopt the euro in 2009. However, the latest data available on growth and transparency reported in Tables 1 and 2 predate those events, so we include all these new euro-area entrants under the EU NMS heading. In addition to the latter grouping, we distinguish between two other potential future euro area countries, namely, non-euro-area nonNMS EU countries and EU accession countries. ${ }^{5}$ Of the three non-euro-area country subgroups considered, NMS and EU accession countries comprise catching-up countries. NMS' pre-accession phase was characterized by structural transformations of their economies, real exchange rate appreciation and rapid capital inflows. This could be seen as a road map for EU accession countries, depending inter alia on market participants' perception about the likelihood of eventual accession.

The growth dynamism of NMS appears to have been higher than in the euro area immediately prior to EMU and also in the period since 1999. This is true for growth in both real GDP and labor productivity (including TFP growth when available). The only two cases where the euro area outpaced NMS concern poor labor productivity growth for Cyprus and Malta in the period 1999-2005. EU accession countries have exhibited diverse growth behavior, characterized by strong dynamism in many cases and poor performances in a smaller number of experiences. The latter include developments in real GDP in Bulgaria and labor productivity in Macedonia and Romania in the period 1993-1998, as well as labor productivity in Bulgaria since 1999. Turning to monetary transparency indicators, both NMS and EU accession countries had diverse scores in both 1998 and in the latest year for which data are collected. Concentrating on the final year for which

${ }^{5}$ Bulgaria and Romania have joined the EU after the more recent year considered in this paper. These countries are here accordingly classified as EU accession countries. 
transparency scores are available, data for EU accession countries are basically those reported by DE, pointing to lower transparency than in the euro area. For Turkey, the CM measure instead finds the country more transparent than the euro area. In the case of NMS, these two sources of information do not coincide in the rankings relative to the euro area, with $\mathrm{CM}$ tending to rate NMS more transparent (safe for Slovenia) and DE instead giving the euro area higher transparency scores (safe for the Czech Republic). Within the NMS group, the DE measure shows that some countries (Czech Republic, Hungary and Poland) recently exhibited more transparent monetary policies than the rest of these countries, which is broadly corroborated by the CM indicator - admittedly less well represented concerning NMS and accession countries.

Finally, unlike NMS and EU accession countries, non-euro-area non-NMS EU economies are advanced economies. They tend to display somewhat different features concerning transparency and growth. Tables 1 and 2 show that Sweden and UK outperformed the euro area as a whole in terms of both growth indicators (since the early 1990s) and transparency (both in 1998 and more recently). Instead, relative to the euro area Denmark exhibited similar growth indicators and worse transparency scores, albeit the latter are only available from DE.

In sum, the existing evidence on growth indicators and transparency scores points to very diverse experiences across the catching-up countries considered and over time. It is worth mentioning that uncertainty about the link between growth and transparency indicators among relevant catching-up economies has also been affected by differences across data sources available for transparency scores - less so in the case of current euro area countries' catching-up process prior to euro adoption than for accession countries and especially NMS. Cross-country differences in the link between growth and transparency suggest that, in order to better understand the roles of transparency and catching up in a currency union, a good starting point is to develop a general setup that could be applied to specific cases by the interested analyst. To that task we devote the remainder of the paper.

\section{A Simple Model}

Challenges posed to common currency areas arise inter alia from structural supply-side discrepancies among member states and country-specific shocks to unobservable monetary policy goals. Here we set up a simple model that allows us to examine both sets of issues. 


\section{A. Output and Inflation}

Let us define a fast growing small open economy as country $h$ and its larger partner $f$. Both economies produce traded $(T)$ and non-traded $(N)$ goods. We use indices $i=h ; f$ for countries and $k=T ; N$ for sectors. All variables are in deviations from steady state. All parameters are positive. All shocks are of the zero-mean, constant variance type, uncorrelated with each other at the country level, but allowed to be correlated across countries.

Output (in $\log$ ) can be aggregated over traded and non-traded sectors as follows:

$$
y_{i}=\gamma_{i} y_{i}^{T}+\left(1-\gamma_{i}\right) y_{i}^{N}
$$

where $\gamma_{i}$ denotes the share of the traded goods in total output. The inflation rate is a weighed average of the price of traded goods, $\pi_{i}^{T}$, and the price of non-traded goods, $\pi_{i}^{N}$ :

$$
\pi_{i}=\gamma_{i} \pi_{i}^{T}+\left(1-\gamma_{i}\right) \pi_{i}^{N}
$$

\section{B. Sectoral Productivity and Relative Price Adjustments}

Sectoral output is produced using a linear technology:

$$
y_{i}^{k}=\Xi_{i}^{k}+l_{i}^{k}
$$

where $\Xi_{i}^{k}$ is TFP and $l_{i}^{k}$ employment in sector $k$ (both in logs). Aggregating over sectors gives:

$$
y_{i}=\Xi_{i}+\gamma_{i} l_{i}^{T}+\left(1-\gamma_{i}\right) l_{i}^{N}
$$

where $\Xi_{i} \equiv \gamma_{i} \Xi_{i}^{T}+\left(1-\gamma_{i}\right) \Xi_{i}^{N}$ measures overall TFP in country $i$. The sectoral demands for labor are derived by equating the marginal product of labor to the producer real wage:

$$
l_{i}^{k}=p_{i}^{k}+y_{i}^{k}-w_{i}
$$

where $p_{i}^{k}$ is the $k$-sector price level and $w_{i}$ is the nominal wage rate (both in logs). The nominal wage is equalized across sectors. The latter expression can be rearranged as follows:

$$
p_{i}^{N}-p_{i}^{T}=\left(y_{i}^{T}-l_{i}^{T}\right)-\left(y_{i}^{N}-l_{i}^{N}\right)
$$


Using this (3) and (6), and then taking growth rates, yields:

$$
\pi_{i}^{N}-\pi_{i}^{T}=\xi_{i}^{T}-\xi_{i}^{N}
$$

where $\pi_{i}^{k}$ and $\xi_{i}^{k}$ denotes the change in $p_{i}^{k}$ and $\Xi_{i}^{N}$, respectively. Equation (7) captures a Balassa-Samuelson effect, whereby if TFP growth in the traded sector is larger than in the non-traded sector, then non-traded inflation will be faster than that of traded goods.

\section{Real Exchange Rate Pressures}

We define $q_{i}^{T}$ as the relative tradable inflation between countries $i$ and $f$ expressed in country is currency. If $s$ is the rate of change in the nominal exchange rate (the amount of country $h$ 's currency per unit of $f$ 's currency), the definition of $q_{i}^{T}$ implies that $q_{h}^{T}=\pi_{f}^{T}+s-\pi_{h}^{T}$, which can be interpreted as changes in the deviation from the law of one price between the two countries. (This level of this deviation is left unconstrained at the start of the analysis.) Moreover, by construction $q_{i}^{T}=0$. Using these expressions, together with (2) and (7), we obtain

$$
\begin{gathered}
\pi_{h}=\pi_{f}^{T}+s+\psi_{h} \\
\pi_{f}=\pi_{f}^{T}+\psi_{f}
\end{gathered}
$$

where $\Psi_{i} \equiv\left(1-\gamma_{i}\right)\left(\xi_{i}^{T}-\xi_{i}^{N}\right)-q_{h}^{T}$. The rate of change in the real exchange rate can be defined as $e=\pi_{f}+s-\pi_{h}$. Note that a negative e represents a real appreciation for country $h$. Using the latter two definitions, together with (8) and (9), we can express the change in the real exchange rate as $e=-\left(\psi_{h}-\psi_{f}\right)$. The latter expression, together with the definition of $\psi_{i}$, leads to:

$$
e=-\left(1-\gamma_{h}\right)\left(\xi_{h}^{T}-\xi_{h}^{N}\right)+\left(1-\gamma_{f}\right)\left(\xi_{f}^{T}-\xi_{f}^{N}\right)-q_{h}^{T}
$$

From (10), one observes that there are two forces contributing to affect the real exchange rate. Let us analyze these two forces in turn for the case of a negative $e$. First, one factor inducing a real appreciation is a higher differential between $h$ and $f$ in TFP between the tradable and non-tradable sectors. That is, $\left(\xi_{h}^{T}-\xi_{h}^{N}\right)>\left(\xi_{f}^{T}-\xi_{f}^{N}\right)$. This factor is bigger if country $f$ is more open $\left(\gamma_{h}<\gamma_{f}\right)$. This is an implication of the Balassa-Samuelson mechanism regarding exchange rate developments. Second, a real appreciation would result from a further deviation from the law of one price between our two countries $\left(q_{h}^{T}>0\right)$.

We shall below relate fluctuations in e to sectoral productivity shocks. For this 
purpose, it is useful to group the latter shocks hitting country $i$ in the disturbance $\tau_{i}$, which we define as a shock to variable $\Psi_{i}$, that is, $\tau_{i} \equiv \psi_{i}-\mathrm{E}\left(\psi_{i}\right)$, where $\mathrm{E}\left(\psi_{i}\right)$ denotes the unconditional expectation of $\psi_{i}{ }^{6}$ Finally, unexpected developments in exchange rates are described by $\tau_{e} \equiv-\left(\tau_{h}-\tau_{f}\right)$. In what follows, we shall interpret changes to $\tau_{e}$ as driven by sectoral productivity shocks in country $h$ relative to $f$, that is, as a stochastic Balassa-Samuelson effect. ${ }^{7}$ We also assume that $\tau_{e}$ is distributed as an i.i.d. white noise error with zero mean and variance $\sigma_{\tau_{e}}^{2}$.

\section{Aggregate Supply}

We postulate an aggregate supply schedule of the form

$$
y_{i}=\alpha_{i}\left(\pi_{i}-\pi_{i}^{e}\right)+\varepsilon_{i}
$$

where $\alpha_{i}$ is the output-inflation tradeoff and $\varepsilon_{i}$ is an i.i.d. white noise error with zero mean and variance $\sigma_{\varepsilon_{i}}^{2}$. The inverse of the output-inflation tradeoff, $\alpha_{i}^{\prime} \equiv 1 / \alpha_{i}$, we refer to as the supply slope. A steeper supply curve is known to entail larger monetary stabilization costs in the event of aggregate productivity shocks. Parameter $\alpha_{i}$ may reflect cross-country structural differences. One country-specific factor affecting the output-inflation tradeoff is the degree of openness (as measured by $\left.\gamma_{i}\right)$. Romer(1993) shows that trade openness makes the supply curve steeper (smaller $\alpha_{i}$ ) by amplifying the inflationary effect from a given real exchange rate depreciation associated with output expansion. In turn, Alesina et al.(2005) provide evidence that trade openness is inversely related to country size. The idea would be that trade openness augments the size of the country's market, thereby raising the advantages of small size. Furthermore, the smaller the country the stronger its interest in engaging in international market transactions. It is however worth stressing that the connection between size and openness is far from simple, involving a wide array of economic, historical and socio-cultural considerations (Alesina and Spolaore, 2003). We will revisit the relevance of the openness-size nexus in our conclusions.

\footnotetext{
${ }^{6}$ In what follows, $E(x)$ denotes the unconditional expectation of any variable $x$, whereas $\tilde{E}(x)$ is the corresponding private-sector expectation.

${ }^{7}$ That is, we do not allow further unexpected deviations from the law of one price to weigh on $\tau_{e}$.
} 


\section{Autonomous Monetary Policy}

An autonomous central bank decides policy at the country level. Its loss function is assumed to be

$$
L_{i}=\frac{1}{2}\left[\left(y_{i}-\kappa_{i}\right)^{2}+\chi\left(\pi_{i}-\theta_{i}\right)^{2}\right]
$$

$L_{i}$ penalizes deviations of output and inflation from targets $\kappa_{i}$ and $\theta_{i}$, respectively. Parameter $\chi$ is the weight put on price stability relative to output stability. Inflation and output targets are stochastic, with $\theta_{i} \sim N\left(\bar{\theta}_{i}, \sigma_{\theta_{i}}^{2}\right)$ and $\kappa_{i} \sim N\left(\bar{\kappa}_{i}, \sigma_{\kappa_{i}}^{2}\right.$, and $\theta_{i}$ and $\kappa_{i}$ independent.

Following Geraats(2007), we consider two different informational asymmetries between the central bank and the private sector. First, the private sector fails to observe the monetary authority's inflation target $\theta_{i}$ and output target $\kappa_{i}$. Instead, it receives the public signals

$$
\begin{aligned}
& \xi_{i}^{\theta}=\theta_{i}+\zeta_{i} \\
& \xi_{i}^{\kappa}=\kappa_{i}+\eta_{i}
\end{aligned}
$$

where $\zeta_{i}$ and $\eta_{i}$ are i.i.d. white noise. Noise terms $\zeta_{i}$ and $\eta_{i}$ capture errors made by the private sector in interpreting the monetary authority's communication. The central bank observes these terms' actual distributions $\varsigma_{i} \sim N\left(\bar{\theta}_{i}, \sigma_{\varsigma i}^{2}\right)$ and $\eta_{i} \sim N\left(\bar{\kappa}_{i}, \sigma_{\eta_{i}}^{2}\right)$. From this point of view, the degree of transparency associated with signals $\xi_{i}^{\theta}$ and $\xi_{i}^{\kappa}$ can be described by

$$
\tau_{i}^{\theta} \equiv \frac{\sigma_{\theta_{i}}^{2}}{\sigma_{\theta_{i}}^{2}+\sigma_{\zeta_{i}}^{2}} ; \quad \text { and } \quad \tau_{i}^{\kappa} \equiv \frac{\sigma_{\kappa_{i}}^{2}}{\sigma_{\kappa_{i}}^{2}+\sigma_{\eta_{i}}^{2}}
$$

respectively, where $0 \leq \tau_{i}^{\theta}, \tau_{i}^{\kappa} \leq 1$. This measure of accuracy is analogous to that introduced by Faust and Svensson(2002). When $\sigma_{\varsigma_{i}}^{2}=\sigma_{\eta_{i}}^{2}=0$, the signals $\xi_{i}^{\theta}$ and $\xi_{i}^{\mathrm{K}}$ transmit $\theta_{i}$ and $\kappa_{i}$ without any noise. Thus, there is perfect actual transparency about the central bank's targets.

Unlike the central bank, the public does not know the actual stochastic distributions of $\theta_{i}, \kappa_{i}, \zeta_{i}$ and $\eta_{i}$. Instead, the public uses the perceived distributions $\theta_{i} \sim N\left(\bar{\theta}_{i}, \tilde{\sigma}_{\theta_{i}}^{2}\right), \kappa_{i} \sim N\left(\bar{\kappa}_{i}, \tilde{\sigma}_{\kappa_{i}}^{2}\right), \varsigma_{i} \sim N\left(\bar{\theta}_{i}, \tilde{\sigma}_{\varsigma_{i}}^{2}\right)$ and $\eta_{i} \sim N\left(\bar{\kappa}_{i}, \tilde{\sigma}_{\eta_{i}}^{2}\right)$. As a result, the perceived degrees of transparency are given by 


$$
\tilde{\tau}_{i}^{\theta}=\frac{\tilde{\sigma}_{\theta_{i}}^{2}}{\tilde{\sigma}_{\theta_{i}}^{2}+\tilde{\sigma}_{\varsigma_{i}}^{2}} ; \quad \text { and } \quad \tilde{\tau}_{i}^{\kappa}=\frac{\tilde{\sigma}_{\kappa_{i}}^{2}}{\tilde{\sigma}_{\kappa_{i}}^{2}+\tilde{\sigma}_{\eta_{i}}^{2}}
$$

respectively, where $0 \leq \tilde{\tau}_{i}^{\theta}, \tilde{\tau}_{i}^{\mathrm{K}} \leq 1$.

Monetary policy is assumed to be conducted under discretion. Events unfold as follows. First, the inflation target $\theta_{i}$ and output target $\kappa_{i}$ are realized and observed by the monetary authority. Then, the public receives the signals $\xi_{i}^{\theta}$ and $\xi_{i}^{\kappa}$, which are an input to $\pi_{i}^{e}$, the private-sector rational expectations about inflation. Next, the aggregate supply shock $\varepsilon_{i}$ and the sectoral productivity shock $\tau_{e}$ are realized and observed by the central bank. Finally, the central bank is assumed to choose inflation $\pi_{i}$, which implies a level of output $y_{i}$.

The central bank minimizes the expected value of (12) with respect to $\pi_{i}$ subject to supply (11), given private-sector inflation expectations $\pi_{i}^{e}$. This yields optimal inflation and output as

$$
\begin{gathered}
\pi_{i}=\phi_{i}\left(\pi_{i}^{e}-\frac{\varepsilon_{i}}{\alpha_{i}}+\frac{\chi}{\alpha_{i}^{2}} \theta_{i}+\frac{\kappa_{i}}{\alpha_{i}}\right) \\
y_{i}=\left(1-\phi_{i}\right) \alpha_{i}\left(-\pi_{i}^{e}+\frac{\varepsilon_{i}}{\alpha_{i}}+\theta_{i}+\frac{\alpha_{i}}{\chi} \kappa_{i}\right)
\end{gathered}
$$

where $\phi_{i} \equiv \alpha_{i}^{2} /\left(\alpha_{i}^{2}+\chi\right)$. Equation (17) conveys the familiar outcome that inflation is increasing in the inflation target $\theta_{i}$, the output target $\kappa_{i}$ and private-sector inflation expectations $\pi_{i}^{e}$, and decreasing in the aggregate supply disturbance $\varepsilon_{i}$.

Private-sector inflation expectations depend on perceptions regarding the central bank's inflation target $\theta_{i}$ and output target $\kappa_{i}$. By allowing for asymmetric information about the degree of accuracy of monetary policy signals, private-sector transparency misperceptions (that is, deviations between perceived and actual stochastic volatility) are introduced. Using public signals (13) and (14), alongside (16), private-sector rational expectations of policy targets amount to ${ }^{8}$

$$
\begin{aligned}
& \tilde{E}\left[\theta_{i} \mid \xi_{i}^{\theta}\right]=\tilde{\tau}_{i}^{\theta_{i}} \xi_{i}^{\theta}+\left(1-\tilde{\tau}_{i}^{\theta}\right) \bar{\theta}_{i} \\
& \tilde{E}\left[\kappa_{i} \mid \xi_{i}^{\kappa}\right]=\tilde{\tau}_{i}^{\kappa} \xi_{i}^{\kappa}+\left(1-\tilde{\tau}_{i}^{\kappa}\right) \bar{\kappa}_{i}
\end{aligned}
$$

Transparency perceptions $\tilde{\tau}_{i}^{\theta}$ and $\tilde{\tau}_{i}^{\kappa}$ thus impact the updating of private-sector

\footnotetext{
${ }^{8}$ Here, we use the property that, for two jointly normally distributed variables $\mathrm{x}$ and $\mathrm{z}$, $E[x \mid z]=E[x]+\frac{\operatorname{Cov}[x, z]}{\operatorname{Var}[z]}(z-E[z])$.
} 
expectations. As a result, private-sector inflation expectations are found to be

$$
\pi_{i}^{e}=\tilde{\theta}_{i}+\tilde{\tau}_{i}^{\theta}\left(\theta_{i}-\bar{\theta}_{i}\right)+\tilde{\tau}_{i}^{\theta} \varsigma_{i}+\frac{\alpha_{i}}{\chi}\left[\bar{\kappa}_{i}+\tilde{\tau}_{i}^{\kappa}\left(\kappa_{i}-\bar{\kappa}_{i}\right)+\tilde{\tau}_{i}^{\kappa} \eta_{i}\right]
$$

Substituting (21) into (17) and (18) yields the following levels of inflation and output:

$$
\begin{aligned}
\pi_{i}= & \bar{\theta}_{i}+\phi_{i}\left(\frac{\chi}{\alpha_{i}^{2}}+\tilde{\tau}_{i}^{\theta}\right)\left(\theta_{i}-\bar{\theta}_{i}\right)+\dot{\phi}_{i} \tilde{\tau}_{i}^{\theta} \varsigma_{i}+\frac{\alpha_{i}}{\chi} \bar{\kappa}_{i}+\phi_{i}\left(\frac{1}{\alpha_{i}}+\frac{\alpha_{i} \tilde{\tau}^{\kappa}}{\chi} \tau_{i}^{\kappa}\right)\left(\kappa_{i}-\bar{\kappa}_{i}\right) \\
& +\phi_{i} \frac{\alpha_{i} \tilde{\tau}^{\kappa}}{\chi} \eta_{i} \eta_{i}-\phi_{i} \frac{\varepsilon_{i}}{\alpha_{i}} \\
y_{i}= & \left(1-\phi_{i}\right) \alpha_{i}\left[\left(1-\tilde{\tau}_{i}^{\theta}\right)\left(\theta_{i}-\bar{\theta}_{i}\right)-\tilde{\tau}_{i}^{\theta} \varsigma_{i}\right]+\phi\left[\left(1-\tilde{\tau}_{i}^{\kappa}\right)\left(\kappa_{i}-\bar{\kappa}_{i}\right)-\tilde{\tau}_{i}^{\kappa} \eta_{i}\right] \\
& +\left(1-\phi_{i}\right) \varepsilon_{i}
\end{aligned}
$$

Optimal inflation and output levels depend on the central bank's targets $\theta_{i}$ and $\kappa_{i}$, the private sector's priors $\bar{\theta}_{i}$ and $\bar{\kappa}_{i}$, the signal noise terms $\varsigma_{i}$ and $\eta_{i}$, and the aggregate supply disturbance $\varepsilon_{i}$. Although the degrees of transparency $\tilde{\tau}_{i}^{\theta}$ and $\tilde{\tau}_{i}{ }^{K}$ influence inflation and output, they have no effect on the values of these two variables that both the central bank and the public rationally expect. In the case of perfect (actual and perceived) transparency $\left(\tilde{\tau}_{i}^{\theta}=\tilde{\tau}_{i}^{\kappa}=1\right.$, and $\left.\varsigma_{i}=\eta_{i}=0\right)$, the equations become simply $\pi_{i}=\bar{\theta}_{i}+\left(\alpha_{i} / \chi\right) \bar{\kappa}_{i}-\left(\phi_{i} / \alpha_{i}\right) \varepsilon_{i}$ and,$y_{i}=\left(1-\phi_{i}\right) \varepsilon_{i}$ which gives the standard result that the targets $\theta_{i}$ and $\kappa_{i}$ influence inflation but fail to affect output.

To derive the optimal degrees of actual and perceived transparency, substitute (17) and (18) into (12) using (21), and rearrange to get

$$
L_{i}=\frac{1-\phi_{i}}{2}\left[\alpha\left(\tilde{\tau}_{i}^{\theta}-1\right)\left(\theta_{i}-\bar{\theta}_{i}\right)+\alpha_{i} \tilde{\tau}_{i}^{\theta} \varsigma_{i}+\frac{\bar{\kappa}_{i}}{1-\phi_{i}}+\left(1+\frac{\alpha_{i}^{2}}{\chi} \tilde{\tau}_{i}^{\kappa}\right)\left(\kappa_{i}-\bar{\kappa}_{i}\right)+\frac{\alpha_{i}^{2}}{\chi} \tilde{\tau}_{i}^{\kappa} \eta_{i}-\varepsilon_{i}\right]^{2}
$$

Taking unconditional expectations based on the actual distributions and substituting for $\tilde{\sigma}_{\varsigma i}^{2}$ and $\tilde{\sigma}_{\eta i}^{2}$ using (16) yields

$$
\begin{aligned}
E\left(L_{i}\right)= & \frac{1-\phi_{i}}{2}\left[\alpha_{i}^{2}\left(1-2 \tilde{\tau}_{i}^{\theta}+\frac{\left(\tilde{\tau}_{i}^{\theta}\right)^{2}}{\tau_{i}^{\theta}}\right)\right] \sigma_{\theta_{i}}^{2}+\left(\frac{\tilde{\kappa}_{i}}{1-\phi_{i}}\right)^{2} \\
& +\phi_{i}\left(1+2 \frac{\alpha_{i}^{2}}{\chi} \tilde{\tau}_{i}^{\kappa}+\left(\frac{\alpha_{i}^{2}}{\chi}\right) \frac{\left(\tilde{\tau}_{i}^{\kappa}\right)^{2}}{\tau_{i}^{\kappa}}\right) \sigma_{\kappa_{i}}^{2}+\sigma_{\varepsilon_{i}}^{2}
\end{aligned}
$$


Optimization takes into account the constraint that actual and perceived degrees of transparency must lie between 0 and 1. In (25), $E\left(L_{i}\right)$ is decreasing in the actual degrees of transparency $\tau_{i}^{\theta}$ and $\tau_{i}^{\kappa}$, so that it is best to achieve perfect actual transparency $\left(\tau_{i}^{\theta}=\tau_{i}^{\kappa}=1\right)$. It is also optimal to set and $\tilde{\tau}_{i}^{\theta}=\tau_{i}^{\theta}$ and $\tilde{\tau}_{i}^{\kappa}=0$. Taking together, these conditions imply maximum actual and perceived transparency about the inflation target $\left(\tau_{i}^{\theta}=\tilde{\tau}_{i}^{\theta}=1\right)$, while for the output target it is best to have complete actual transparency $\left(\tau_{i}^{\mathrm{K}}=1\right)$ and minimal perceived transparency $\left(\tilde{\tau}_{i}^{\kappa}=0\right)$. These results are reasonable. Perfect transparency (both actual and perceived) about the inflation target, together with perfect actual transparency about the output target, make it simpler for the central bank to achieve its inflation and output targets, thanks to their stabilizing impact on private-sector expectations. At the same time, it is optimal to minimize perceived transparency about the output target in order to avoid the erratic behavior of market expectations about inflation.

\section{The Currency Union}

Under this regime, countries $h$ and $f$ form a monetary union. We assume that the single monetary authority's loss function is

$$
L_{u}=\frac{1}{2}\left[\left(y_{u}-\kappa_{u}\right)^{2}+\chi\left(\pi_{u}-\theta_{u}\right)^{2}\right]
$$

where $u$ denotes the monetary union regime. ${ }^{9}$ In (26), the objective function of the central bank penalizes departures of union-wide output and prices from desired values set to $\kappa_{u}$ and $\theta_{u}$, respectively. The country-level assumptions regarding information, timing of events and error distributions are analogous to those used in the last section. It is worth stressing that the individual countries' targets $\theta_{i}$ and $\kappa_{i}$ are not constrained to be the same, so $\theta_{u}$ and $\kappa_{u}$ should be seen as aggregates derived from potentially different and randomly variable country-specific targets.

For welfare analysis purposes, we define three different types of shocks according to their distribution across the union, namely, asymmetric, idiosyncratic and common. In the case of shocks to aggregate supply $\left(\varepsilon_{i}\right)$ and monetary policy $\left(\theta_{t}, \kappa_{i}, \varsigma_{i}\right.$ and $\left.\eta_{i}\right)$, the three types of shocks are characterized as follows. Shocks are normalized to be of unit magnitude for country $h$, which is - without loss of generality - the focus of our comparisons across regimes. Asymmetric shocks add up to zero at the currency union level; in particular, country $h$ of size $\phi$ is assumed

${ }^{9}$ Unless otherwise noted, union-wide variables are weighted averages using weights $\varphi \in(0,1)$ for country $h$ and $1-\varphi$ for country $f$. 
to face a shock equal to 1 , while country $f$ faces a shock equal to $-\varphi /(1-\varphi)$. Idiosyncratic shocks are those in which shocks to country $h$ equal 1 , and shocks to country $f$ equal 0 . Finally, common shocks are defined to be shocks such that both countries face a shock equal to 1 .

The remaining shock is $\tau_{e}$, which affects sectoral productivity. Country-specific disturbances $\tau_{i}$ enter symmetrically in $\tau_{e}$, and thus $\tau_{i}$ 's must be interpreted somewhat differently from the remaining shocks. An asymmetric sectoral productivity shock obtains when country $h$ faces a shock $\tau_{h}$ equal to 1 and country $f$ faces a shock $\tau_{f}$ equal to -1 ; thus $\tau_{\mathrm{e}}=-2$. In line with the other disturbances, an idiosyncratic sectoral productivity shock takes place when only country $h$ is hit $\left(\tau_{h}=1 ; \tau_{f}=0\right)$, and thus $\tau_{e}=-1$. Finally, a common sectoral productivity shock $\left(\tau_{h}=1 ; \tau_{f}=1\right)$ fails to have any impact on real exchange rates $\left(\tau_{e}=0\right)$.

\section{A. Union-wide Output and Prices}

Aggregating over national Phillips curves (11) yields

$$
y_{u}=\alpha_{i}\left(\pi_{u}-\pi_{u}^{e}\right)+\varepsilon_{u}+\Omega
$$

where $\Omega \equiv \varphi\left(\alpha_{h}-\alpha_{u}\right)\left(\pi_{h}-\pi_{h}^{e}\right)+(1-\varphi)\left(\alpha_{f}-\alpha_{u}\right)\left(\pi_{f}-\pi_{f}^{e}\right)=-\varphi(1-\varphi)\left(\alpha_{h}-\alpha_{f}\right) \tau_{e} \cdot{ }^{10}$

In resemblance to the monetary autonomy case, the currency union's central bank minimizes the expected value of its loss function (26) with respect to $\pi_{u}$ subject to (27), given union-wide (private-sector) inflation expectations $\pi_{u}^{e}$. Optimal inflation and output levels are given by

$$
\begin{gathered}
\pi_{u}=\phi_{u}\left(\pi_{u}^{e}-\frac{\varepsilon_{u}+\Omega}{\alpha_{u}}+\frac{\chi}{\alpha_{u}^{2}} \theta_{u}+\frac{\kappa_{u}}{\alpha_{u}}\right) \\
y_{u}=\left(1-\phi_{u}\right) \alpha_{u}\left(-\pi_{u}^{e}+\frac{\varepsilon_{u}+\Omega}{\alpha_{u}}+\theta_{u}+\frac{\alpha_{u}}{\chi} \kappa_{u}\right)
\end{gathered}
$$

where $\phi_{u} \equiv \alpha_{u}^{2} /\left(\alpha_{u}^{2}+\chi\right)$. Equations (28) and (29) indicate private-sector inflation expectations and unexpected developments in each country help determine $\pi_{u}$ and $y_{u}$. In particular, (28) shows that union-wide inflation is increasing in the inflation target $\theta_{u}$, the output target $\kappa_{u}$ and inflation expectations $\pi_{u}^{e}$, and decreasing in the composite (aggregate plus sectoral) supply disturbance $\varepsilon_{u}+\Omega$. The reaction of union-wide inflation and output to developments in each member state is proportional to each country's size ( $\varphi$ in the case of country $h$ and $1-\varphi$ in the case

\footnotetext{
${ }^{10}$ The latter equality follows from (17) and (18), as well as the definition of $\tau_{e}$.
} 
of $f$ ).

In analogy to the previous section, transparency perceptions $\tilde{\tau}_{u}^{\theta}$ and $\tilde{\tau}_{u}^{\kappa}$ influence private-sector inflation expectations at the currency union level. ${ }^{11}$ The latter can be written as

$$
\pi_{u}^{e}=\bar{\theta}_{u}+\bar{\tau}_{u}^{\theta}\left(\theta_{u}-\bar{\theta}_{u}\right)+\tilde{\tau}_{u}^{\theta} \varsigma_{u}+\frac{\alpha_{u}}{\chi}\left[\bar{\kappa}_{u}+\bar{\kappa}_{u}^{\kappa}\left(\kappa_{u}-\bar{\kappa}_{u}\right)+\tilde{\tau}_{u}^{\kappa} \eta_{u}\right]
$$

The optimal degrees of actual and perceived transparency can be obtained as follows. First, substitute (28) and (29) into (26) using (30), and rearrange to obtain $L_{u}$ as the union-wide counterpart to (24). Second, take unconditional expectations to obtain $E\left(L_{u}\right)$ following analogous steps as in the previous section, which using the definition of $\Omega$ yields

$$
\begin{aligned}
& E\left(L_{u}\right)=\frac{1-\phi_{u}}{2} \alpha_{u}^{2}\left(1-2 \tilde{\tau}_{u}^{\theta}+\frac{\left(\tilde{\tau}_{u}^{\theta}\right)^{2}}{\tau_{u}^{\theta}}\right) \sigma_{\theta_{u}}^{2}+\left(\frac{\bar{\kappa}_{u}}{1-\phi_{u}}\right)^{2} \\
& \left.+\phi_{u}\left(1+2 \frac{\alpha_{u}^{2} \tilde{\tau}^{\kappa}}{\chi}+\left(\frac{\alpha_{u}^{2}}{\chi}\right)^{2} \frac{\left(\tilde{\tau}_{u}^{\kappa}\right)^{2}}{\tau_{u}^{\kappa}}\right) \sigma^{2}{ }_{\kappa_{u}}+\sigma_{\varepsilon_{u}}^{2}+\varphi^{2}(1-\varphi)^{2}\left(\alpha_{h}-\alpha_{f}\right)^{2} \sigma_{\tau_{e}}^{2}\right]
\end{aligned}
$$

In line with what was found for the case of autonomous monetary policy, $E\left(L_{u}\right)$ depends on the volatility of disturbances at the union level as well as a number of structural parameter values. At the optimum the single monetary authority delivers perfect actual and perceived transparency about the inflation target $\left(\tau_{u}^{\theta}=\tilde{\tau}_{u}^{\theta}=1\right)$. For the output target, it is best to have complete actual transparency $\left(\tau_{u}^{\kappa}=1\right)$ and minimal perceived transparency $\left(\tilde{\tau}_{u}^{\mathrm{k}}=0\right)$. The overall mix of actual and perceived transparency is the one that best limits the volatility of private-sector expectations and thus facilitating the task of the single monetary authority.

\section{B. Country-level Welfare}

Our welfare analysis compares country $h$ 's loss function under monetary autonomy $\left(L_{h}\right.$ in (12)) with that derived from currency union membership, $L_{h}^{u}$. The latter loss function is given by

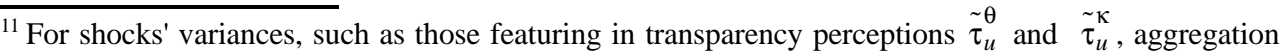
proceeds as follows. For a given country-specific random variable $x_{i}$, the union-wide variance equals $\sigma_{x_{u}}^{2}=\varphi^{2} \sigma_{x_{h}}^{2}+(1-\varphi)^{2} \sigma_{x_{f}}^{2}+2 \varphi(1-\varphi) \sigma_{x_{h} x_{f}}$. This shows that union-wide variability is a function of both country-specific volatility and cross-country correlations.
} 


$$
L_{h}^{u}=\frac{1}{2}\left[\left(y_{h}^{u}-\kappa_{h}\right)^{2}+\chi\left(\pi_{h}^{u}-\theta_{h}\right)^{2}\right]
$$

where $y_{h}^{u}$ and $\pi_{h}^{u}$ are, respectively, country $h^{\prime}$ s output and prices under monetary union.

The values of $y_{h}^{u}$ and $\pi_{h}^{u}$ can be determined as follows. At the optimum, (30) implies that $\pi_{u}^{e}=\theta_{u}+\varsigma_{u}+\left(\alpha_{u} / \chi\right) \bar{\kappa}_{u}$. Union-wide inflation expectations depend on aggregates of individual country shocks $\theta_{i}$ and $\varsigma_{i}$, as well as the aggregate of mean output targets $\bar{\kappa}_{i}$ in a way that is proportional to the union-wide output-inflation tradeoff, $\alpha_{u}$. It is thus reasonable to assume that inflation expectations follow $\pi_{u}^{e}=\theta_{i}+\varsigma_{i}+\left(\alpha_{u} / \chi\right) \bar{\kappa}_{i}$ for $i=h ; f$. Using optimal levels of $\pi_{u}$ and $y_{u}$ obtained by plugging $\pi_{u}^{e}$ into (28) and (29), and taking into account domestic Phillips curves (11), we obtain the following values of $y_{h}^{u}$ and $\pi_{h}^{u}$ :

$$
\begin{gathered}
\pi_{h}^{u}=\theta_{h}+\frac{1}{\varphi\left(\alpha_{h}-\alpha_{f}\right)}\left\{\varphi \alpha_{h}\left(\frac{\alpha_{u}}{\chi} \bar{\kappa}_{h}-\frac{\varepsilon_{h}}{\alpha_{h}}\right)+(1-\varphi) \alpha_{f}\left(\frac{\alpha_{u}}{\chi} \bar{\kappa}_{f}-\frac{\varepsilon_{f}}{\alpha_{f}}\right)\right. \\
\left.-\frac{\alpha_{f} \alpha_{u}}{\chi} \bar{\kappa}_{u}+\frac{\alpha_{u}\left(\alpha_{u}-\alpha_{f}\right)}{\alpha_{u}+\chi}\left(\kappa_{u}-\bar{\kappa}_{u}\right)+\frac{\chi+\alpha_{f} \alpha_{u}}{\alpha_{u}^{2}+\chi}\left(\varepsilon_{u}+\Omega\right)\right\} \\
\left.y_{h}^{u}=\frac{\alpha_{h}}{\varphi\left(\alpha_{h}-\right.}\right)\left\{\varphi \alpha_{f}\left(\frac{\alpha_{u}}{\chi} \bar{\kappa}_{h}-\frac{\varepsilon_{h}}{\alpha_{h}}\right)+(1-\varphi) \alpha_{f}\left(\frac{\alpha_{u}}{\chi} \bar{\kappa}_{f}-\frac{\varepsilon_{f}}{\alpha_{f}}\right)\right. \\
\left.-\frac{\alpha_{f} \alpha_{u}}{\chi} \kappa_{u}+\frac{\alpha_{u}\left(\alpha_{u}-\alpha_{f}\right)}{\alpha_{u}^{2}+\chi}\left(\kappa_{u}-\bar{\kappa}_{u}\right)+\frac{\chi+\alpha_{f} \alpha_{u}}{\alpha_{u}^{2}+\chi}\left(\varepsilon_{u}+\Omega\right)\right\}
\end{gathered}
$$

which can be replaced into (32) to find reference member state's welfare, $L_{h}^{u}$. Due to our previous result that $\tilde{\tau}_{u}^{\kappa}=0$ at the optimum, output target noise $\eta_{i}$ does not play any role in reference country $h$ 's welfare analysis. Moreover, as we have seen, it is optimal for the single monetary authority to deliver complete actual and perceived transparency about the inflation target, implying that this target's signal is provided without noise at the union-wide level $\varsigma_{u}=0$ ). While this could still be consistent with asymmetric non-zero inflation target noise disturbances, we rule this special case out by assuming that $\varsigma_{i}=0$ for $i=h ; f .^{12}$

In expressions (33) and (34), we see that inflation target shocks $\theta_{i}$ only enter as

\footnotetext{
${ }^{12}$ In this context, it may make sense to drop the label "shock" from the optimal realizations of inflation targets, given that they can be deduced from the corresponding signals. As we shall see, inflation targets turn out not to play a major role in our sensitivity analysis, so we do not find it useful to employ a different terminology for $\theta_{i}$ 's.
} 
in a one-to-one relation with domestic inflation. Disturbance $\theta_{h}$ does not influence domestic output, while foreign shock $\theta_{f}$ fails to affect country $h$ 's macroeconomic variables. Moreover, output target shocks only enter (33) and (34) as aggregate disturbance $\kappa_{u}$ (in deviation from its central value, $\bar{\kappa}_{u}$ ), reflecting monetary policy's attempt to limit expected inflation fluctuations arising from union-wide output target uncertainty. Aggregate supply shock $\varepsilon_{i}$ features in (33) and (34) both as country-specific shocks and union-wide aggregates. In section 6 , we will more clearly identify the way in which country $h$ 's macroeconomic variables are driven $\varepsilon_{i}$ by for $i=h ; f$.

The remaining disturbance affecting macroeconomic developments in (33) and (34) is sectoral productivity shock $\tau_{e}$ (featuring in $\Omega$ ). Sectoral shocks do not enter the reference country $h$ 's welfare function (24) under monetary autonomy. Neither do common sectoral disturbances influence reference country's welfare under the monetary union arrangement. In contrast, currency union participation is discouraged by sectoral shocks of the asymmetric or idiosyncratic types, which elicit reactions from the single monetary authority that are unnecessary under monetary autonomy. Overall, thus, the single monetary policy is outperformed by monetary autonomy under sectoral shocks. Given that sectoral shocks would not be expected to be highly and positively correlated in case member states are at different stages in their development process, the occurrence of these shocks can be seen as discouraging catching up countries' participation in a currency union.

\section{Relative Performance and Sensitivity Analysis}

This section conducts a quantitative welfare assessment for a currency union relative to monetary autonomy. We distinguish between sectoral productivity shocks, which only enter the reference country's loss function (32) under a currency union, and shocks hitting aggregate supply and policy targets, which both affect country $h$ 's welfare under both monetary autonomy and currency union. For the latter group of shocks, welfare analysis is more involved, with neither autonomous monetary policy nor the currency union clearly outperforming the other.

\section{A. Benchmark Parameter Values}

The next subsection examines the sensitivity of relative stabilization performance to parameter values. We employ benchmark parameter values 
drawing - when possible - from calibrated small open economy models. The supply schedule parameter $\alpha_{i}$ is assumed to display cross-country variation. Let $\alpha_{i}{ }^{\prime} \equiv 1 / \alpha_{i}$ be its inverse, which represents the reaction of inflation to output. We concentrate on the case of country-specific output-inflation tradeoffs $\alpha_{i}{ }^{\prime},{ }^{13}$ which hover around a central value which is chosen to be $\alpha^{\prime}{ }_{i}=0.4$, as in Ball(1999). We label the difference between high and low alternative values for $\alpha_{i}^{\prime}$ simply as spread $\equiv \bar{\alpha}^{\prime}-\alpha^{\prime}$. In our baseline calibration, we set spread to 0.1 . Our benchmark value for $\varphi$ is 0.1 . Finally, lacking estimates for $\chi$ obtained from small open economies, we use Broadbent and Barro's(1997) value of 2.58, as estimated for the US.

\section{B. Sensitivity Analysis}

Here we evaluate the sensitivity of relative welfare between the two monetary arrangements to changes in key parameter values. In order to do so, we follow Lane(2000) in constructing the relative welfare loss ratio $C_{u h} \equiv L_{h}^{u} / L_{h}$. This ratio expresses reference country $h$ 's loss function under a currency union in proportion to that obtained under monetary autonomy. We set this ratio to one at benchmark parameter values; that is, the ratio's values are to be interpreted in relation to the benchmark case. Exceptionally, under sectoral productivity shocks in $\tau_{e}$ we simply report $L_{h}^{u}$. The reason is that, given that these shocks do not affect the autonomous central bank's loss function, $L_{h}=0$ barring the occurrence of other shocks and the ratio $C_{u h}$ would thus be indeterminate. Finally, it is worth stating upfront that, under the occurrence of disturbances $\theta_{i}$ hitting inflation targets relative welfare is found not to be affected by any parameter change. The reason is that, both under monetary autonomy and currency union, a realization of $\theta_{h}$ has a one-to-one impact on country $h$ 's inflation, while failing to affect domestic output. Moreover, under monetary union $\theta_{f}$ has no effect on country $h$ 's macroeconomic variables under either monetary regime. For these reasons, in our sensitivity analysis we do not discuss the (irrelevant) role of inflation target shocks, for which relative welfare ratio $C_{u h}$ always registers a value of 1 .

Among our key parameters, the supply slope, $\alpha_{i i}{ }^{\prime}$, is assumed to be countryspecific. We look at its changes around a central value, $\alpha_{i}{ }^{\prime}$, as well as changes in the gap between the parameter's high and low alternative values, spread. We also consider variations in the reference country's size, $\varphi$, and the central bank

\footnotetext{
${ }^{13}$ Given that we focus on the perspective of a catching up country, a scenario of uniform supply slopes does not appear to be as relevant.
} 
preference for price stability, $\chi$. We follow Lane(2000) in studying sensitivity to parameter changes conditional on the realization of shocks, which can be of three types, namely, common, idiosyncratic or asymmetric. In doing so, we treat the size and asymmetry of disturbances as given, neglecting the situation where parameter values and the cross-country distribution of shocks vary with the depth of regional integration. $^{14}$

For each range of parameter values, Figures 1 through 4 depict the relative welfare loss as measured by the ratio $C_{u h}$ under aggregate supply and output target shocks (panels A through D in each Figure). Figure 5 reports reference country $h$ 's loss function under a currency union, $L_{h}^{u}$, for the case of sectoral productivity shocks. All of these Figures are shown for different types of reference countries and cross-country distribution of shocks. In studying the factors driving the welfare implications of parameter changes, it is useful to compare the impact on country $h$ 's inflation and output levels under currency union participation (that is, (33) and (34), respectively) with the corresponding values under monetary autonomy (see equations (22) and (23)).

\section{(1) Sensitivity to the Aggregate Supply Slope}

Figure 1 reports sensitivity analysis for $\alpha^{\prime}$ over the range [0.2-0.6]. Under aggregate supply disturbances $\varepsilon_{i}$, in all cases we see that a steeper supply schedule (larger $\alpha^{\prime}$ ) lowers ratio $C_{u h}$, i.e. it raises country $h$ 's relative welfare in a currency union. Using equations (33) and (34), the macroeconomic effects of these shocks are:

$$
\begin{array}{cc}
\frac{\partial \pi_{h}^{u}}{\partial \varepsilon_{h}}=-\frac{\phi_{u}}{\alpha_{u}}\left(1-\frac{\alpha_{h}-\alpha_{u}}{\alpha_{h}-\alpha_{f}}\right) ; & \frac{\partial \pi_{h}^{u}}{\partial \varepsilon_{f}}=-\left(\frac{1-\varphi}{\varphi}\right) \frac{\phi_{u}}{\alpha_{u}}\left(1-\frac{\alpha_{h}-\alpha_{u}}{\alpha_{h}-\alpha_{f}}\right) \\
\frac{\partial y_{h}^{u}}{\partial \varepsilon_{h}}=\left(1-\phi_{u}\right)+\phi_{u} \frac{\alpha_{f}}{\alpha_{u}}\left(\frac{\alpha_{h}-\alpha_{u}}{\alpha_{h}-\alpha_{f}}\right) ; & \frac{\partial y_{h}^{u}}{\partial \varepsilon_{f}}=-\left(\frac{1-\varphi}{\varphi}\right) \phi_{u} \frac{\alpha_{h}}{\alpha_{u}}\left(\frac{\alpha_{u}-\alpha_{f}}{\alpha_{h}-\alpha_{f}}\right)
\end{array}
$$

In the scenario of asymmetric aggregate supply shocks $\left(\varepsilon_{h}=1 ; \varepsilon_{f}=-\varphi /(1-\varphi)\right)$, from (35) and (36) it can be found that neither inflation nor output is affected by $\alpha^{\prime}$. An asymmetric supply shock in country $h$ leaves $\pi_{h}^{u}$ unchanged, while raising

\footnotetext{
${ }^{14}$ On this, see Frankel and Rose(1998). Moreover, we do not enter into the debate of whether an intensification of trade flows as a result of currency union participation would turn business cycles more synchronized, thereby raising the likelihood of "common" shocks. Challenging this view, there is evidence that stronger trade integration might lead to further specialization and thus make shocks look more country-specific (Kalemli-Ozcan et al., 2001).
} 
$y_{h}^{u}$ by 1 . Intuitively, the single monetary authority does not react to country-specific supply shocks that offset each other at the union-wide level, being in particular unresponsive to changes in the supply slope. Therefore, under asymmetric disturbances the currency union's relative stabilization performance as measured by $C_{u h}$ is entirely driven by changes occurring under monetary autonomy. A steeper supply curve is a challenge for autonomous monetary policy in the face of $\varepsilon_{h}$, thus favoring the currency union alternative. ${ }^{15}$ This effect carries over to the more complicated scenarios of aggregate supply shocks of the common and idiosyncratic types, even if a number of additional factors are then at play.

Figure 5a (top panel) shows that the impact of higher $\alpha^{\prime}$ is beneficial for the currency union under sectoral productivity disturbances, excepting the (neutral) case of a common shock in which any effect is switched off $\left(\tau_{e}=0\right)$. Under sectoral productivity disturbances of the asymmetric and idiosyncratic types, the single monetary authority decides how much of the realization of $\Omega$ (and thus implicitly $\tau_{e}$ ) will affect union-wide inflation and output, with implications for macroeconomic developments in both countries. With the help of (28) and (29), we can see that a rise in $\alpha^{\prime}$, which reduces $\alpha_{u}$, induces a fall in inflation variability at the union level, at the expense of union-wide output variability. Country $h$ 's macroeconomic variables are affected according to (33) and (34). From the definition of $\tau_{e}$, given $\Omega$, the improvement in country $h$ 's welfare under a currency union can be found to mainly stem from the decline in output variability. ${ }^{16}$

Output target shocks $\kappa_{i}$ are the only types of monetary policy shocks that affect welfare ratio $C_{u h}$. Equations (33) and (34) can be used to express the effect of output target disturbances as

$$
\begin{array}{cc}
\frac{\partial \pi_{h}^{u}}{\partial \kappa_{h}}=\frac{\phi_{u}}{\alpha_{h}}\left(1-\frac{\alpha_{f} \alpha_{h}-\alpha_{u}}{\alpha_{u}} \frac{\alpha_{h}-\alpha_{f}}{\alpha_{f}}\right) & \frac{\partial \pi_{h}^{u}}{\partial \kappa_{f}}=\left(\frac{1-\varphi}{\varphi}\right) \frac{\phi_{u}}{\alpha_{u}}\left(\frac{\alpha_{u}-\alpha_{f}}{\alpha_{h}-\alpha_{f}}\right) \\
\frac{\partial y_{h}^{u}}{\partial \kappa_{h}}=\phi_{u}\left[1-\frac{\alpha_{f}}{\alpha_{u}}\left(\frac{\alpha_{h}-\alpha_{u}}{\alpha_{h}-\alpha_{f}}\right)\right] ; & \frac{\partial y_{h}^{u}}{\partial \kappa_{h}}=\left(\frac{1-\varphi}{\varphi}\right) \phi_{u} \frac{\alpha_{f}}{\alpha_{u}}\left(\frac{\alpha_{u}-\alpha_{f}}{\alpha_{h}-\alpha_{f}}\right)
\end{array}
$$

In Figure 1, there is a clear difference between shocks $\kappa_{i}$ of the asymmetric type and the remaining two. As we have seen, output target shock only impact domestic

\footnotetext{
${ }^{15}$ Indeed, loss function $L_{h}$ in (24) carries a factor $1-\phi_{h}$ that varies positively with $\alpha^{\prime}$. Therefore, an increase in the latter parameter induces a deterioration in autonomous monetary policy's stabilization properties.

${ }^{16}$ This reduction in country $h$ 's output variability results rather directly from the steeper supply curve, as captured by declining factor $\alpha_{h}$ in (34).
} 
Figure 1. Relative Welfare: Sensitivity to $\alpha^{\prime}$

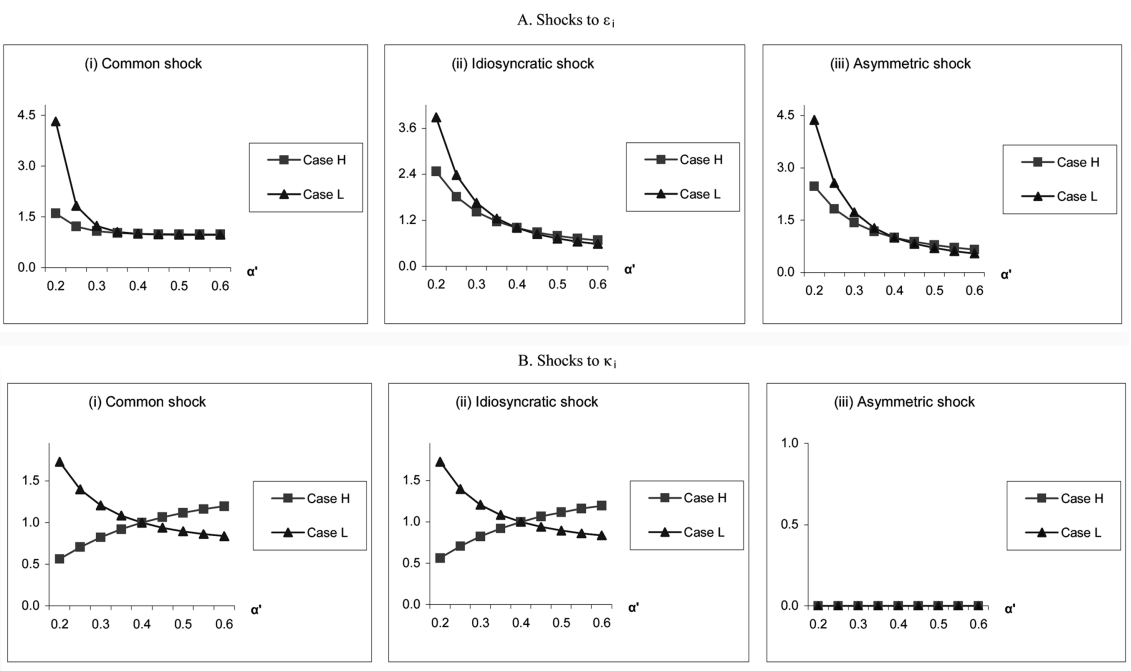

macroeconomic developments as part of the union-wide aggregate $\kappa_{u}$. In the case of asymmetric output target shocks (which vanish at the union level), there is a zero contribution of $\kappa_{i}$ 's to the reference country's welfare loss under currency union membership, $L_{h}^{u}$. Therefore, the single monetary authority always performs better than the autonomous policymaker (with the welfare loss under monetary autonomy, $L_{h}$, rising in reaction to $\kappa_{h}$ ). In the scenarios of output target disturbances of the common and idiosyncratic types, which monetary arrangement relatively gains from a higher value of $\alpha^{\prime}$ depends on the reference country's supply slope type. For these shocks, Figure 1 shows that, as inflation becomes more responsive to output, a currency union's stabilization performance improves for reference country of type $\mathrm{L}$ and deteriorates in Case $\mathrm{H}$. The latter result can be attributed to the fact that, while country $h$ in this case faces a steeper supply schedule and thus a less favorable output-inflation tradeoff than country $f$, a higher $\alpha^{\prime}$ erodes this difference in relative terms. Therefore, a type-H reference country receives in the margin less attention from the single monetary authority. The opposite occurs to a type-L country, who gains relatively more from currency union participation as a result of an across-the-board increase in supply slopes. 
Figure 2. Relative Welfare: Sensitivity to Spread
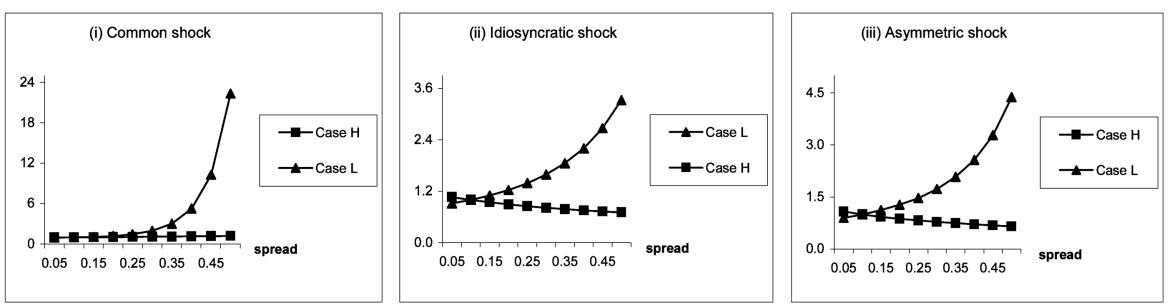

B. Shocks to $\kappa_{i}$
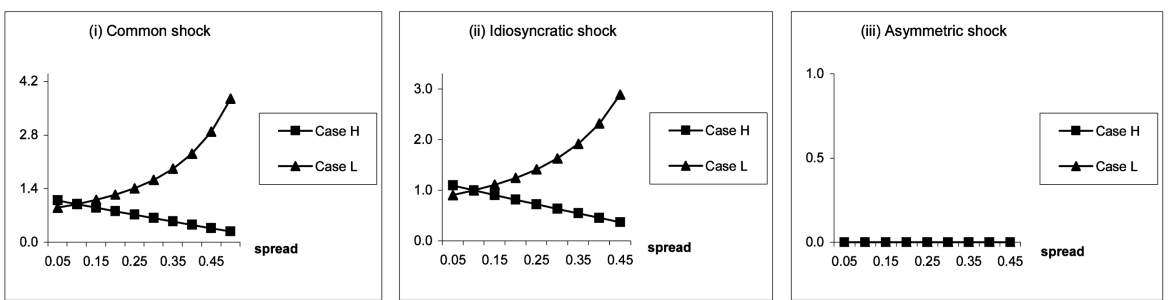

\section{(2) Sensitivity to the Gap between National Supply Slopes}

In Figure 2, we vary spread over [0.05-0.5]. Growing cross-country differences in the value of $\alpha_{i}^{\prime}$ lead to somewhat contrasting results between Cases $\mathrm{H}$ and $\mathrm{L}$. More concretely, as spread increases a currency union's stabilization performance appears to deteriorate for Case L (especially under common shocks). For a type $\mathrm{H}$ reference country, a rise in spread makes the single monetary authority's task simpler, except in the case of common shocks $\left(\varepsilon_{h}=1 ; \varepsilon_{f}=1\right)$ where a slight deterioration is instead found. These results can be best understood in two steps. First, there is a channel tending to improve the currency union's performance when reference country $h$ exhibits a high value for $\alpha_{h}$, while the opposite is true for Case L. As explained before, under Case $\mathrm{H}$ country $h$ displays a steeper supply curve and thus a less favorable output-inflation tradeoff at home, whereas a type-L reference country faces a flatter supply schedule and thus a favorable tradeoff for autonomous monetary policy. Second, the role of foreign supply shock $\varepsilon_{h}$ explains why, as spread rises, a currency union's stabilization performance no longer improves in Case $\mathrm{H}$ and further deteriorates in Case $\mathrm{L}$. While the worsening thus occurs regardless of the country type, $\varepsilon_{f}$ exerts a somewhat different effect depending on whether $\alpha_{h}$ is high or low.

Figure 5a (bottom panel) shows that, as also found for $\alpha$, changes in spread fail to exert any influence on welfare in the event of common sectoral productivity 
disturbances (which leave real exchange rates unaffected). For sectoral shocks of the idiosyncratic and asymmetric types, a rise in spread leads to contrasting results between Cases $\mathrm{H}$ and L. Specifically, under these scenarios for disturbance $\tau_{e}$ a currency union's stabilization performance appears to improve for Case $\mathrm{H}$ as spread increases, while deteriorating for Case L. For a type $\mathrm{H}$ reference country, the improvement can be traced to the result that, in light of the implied steeper supply schedule for the reference country, a higher spread leads to a much larger reduction in output variability than it raises inflation variability. In contrast, in Case L country $h$ faces a flatter schedule as a result of a larger gap between national supply slopes, with lower inflation variability implying larger gains from currency union participation than the losses derived from higher output volatility.

Regarding output target disturbances $\kappa_{i}$, those of the asymmetric type always favor currency union participation, which helps insulate country $h$ from macroeconomic fluctuations still induced by the shock under autonomous monetary policy. In contrast, for common and idiosyncratic $\kappa_{i}$ 's a larger gap in national supply slopes improves monetary union stabilization in Case $\mathrm{H}$, while the opposite is true for Case L. ${ }^{17}$ Intuitively, the difference lies in that, in the face of an output target shock, if is high (Case H) country $h$ would face a steeper supply schedule as spread goes up, implying larger inflation variability due to autonomous monetary policy reactions. This increases relative welfare under currency union participation for a type-H reference country, whose situation requires more attention from the single monetary authority (in light of the deteriorating outputinflation tradeoff) the steeper that country's supply curve. The opposite is true for Case L, where an increase in spread results in an even flatter supply and thus a more favorable policy tradeoff.

\section{(3) Sensitivity to Country Size}

Figure 3 reports sensitivity analysis for $\varphi$ over the range [0.05-0.5]. Country size may affect welfare only in the currency union. Moreover, in a currency union the reference country's welfare is not changed in the event of supply shocks of the common and asymmetric types. Under the latter shock type, size does not matter since these disturbances are defined to exactly offset each other at the union level.

\footnotetext{
${ }^{17}$ This relates to the result that, as a consequence of a rising spread, the ratio $\phi_{h}$ affecting country $h$ 's inflation and output levels under monetary autonomy fluctuates (see (22) and (23)) by more than $\phi_{u}$ which determines domestic macroeconomic variables under monetary union membership in (35) and (36).
} 
Figure 3. Relative Welfare: Sensitivity to $\varphi$
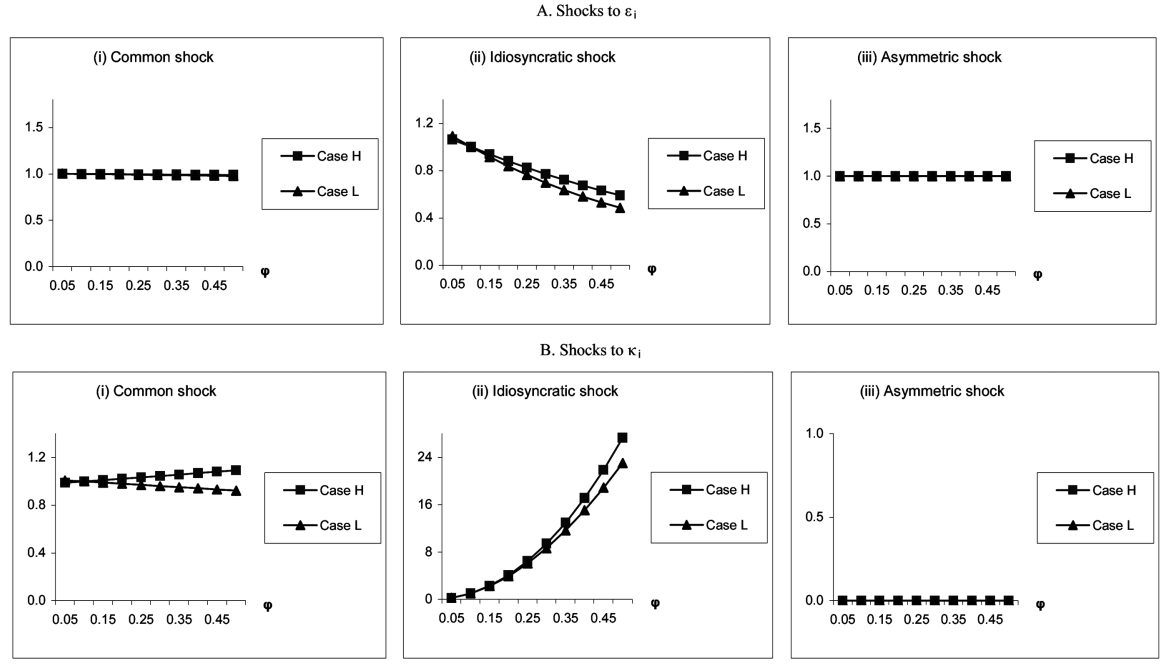

The magnitude of these disturbances in both countries adjusts to changes in their respective size, with $\varphi$ having no influence on relative welfare. In contrast to the other two scenarios, under idiosyncratic supply shocks relative welfare from monetary union membership improves. Regardless of whether the reference country exhibits a steep or flat supply schedule, a rise in implies that the actions taken by the currency union's central bank are better suited to the country's needs, that is, more aligned with the policy followed under monetary autonomy.

Figure 5b (top panel) shows that also changes in $\varphi$ have no effect on the relative merits of the two monetary regimes considered here for common shocks. Currency union participation is instead favored by the occurrence of sectoral productivity disturbances of the asymmetric and idiosyncratic types. The driving factor behind the improvement is that a larger reference receives more attention from the single monetary authority, implying lower macroeconomic volatility in country $h$.

Finally, in the case of shocks to output targets $\kappa_{i}$ we see that autonomous monetary policy is once more outperformed by the currency union arrangement in the face of asymmetric shocks. In the event of output target shocks of the common

\footnotetext{
${ }^{18}$ The latter finding intuitively conforms with the notion that a larger reference country receives more attention from the single monetary authority, thereby inducing a policy that better suits the country's needs. However, as $\varphi$ rises, consideration of output target disturbances shows that monetary union stabilization performance is hampered when the shocks are idiosyncratic and - for the case of a steepsupply reference country - of the common type.
} 
and idiosyncratic types, our results qualify the previously reported for aggregate and sectoral supply shocks, which indicates that higher country size favors country $h$ 's currency union membership. ${ }^{18}$ In the event of idiosyncratic shocks, country $h$ 's larger economic weight harms currency union participation simply by increasing the magnitude of the union-wide shocks, which amounts to the size of the domestic shock times $\varphi$. For common shocks, there are contrasting results between Case L and Case $\mathrm{H}$, which involves the role of foreign shock $\kappa_{f}$ (even if dampened by the reference country's larger size). A higher $\varphi$ implies that union-wide supply slope $\alpha_{u}$ rises in Case L and falls in Case H. This has implications for how the single monetary authority splits the shock's impact between inflation and output in general (via its influence on $\phi_{u}$ ), as well as on how $\kappa_{f}$ affects reference country's macroeconomic variables in particular. It turns out that the foreign shock raises macroeconomic variability for a steep-supply reference country and reduces it for a flat-supply one, thereby discouraging monetary union membership in the former case and favoring it in the latter. ${ }^{19}$

\section{(4) Sensitivity to the Preference for Price Stability}

In Figure 4, we vary the central bank's preference parameter $\chi$ over [0.5-5]. Under aggregate supply disturbances $\varepsilon_{i}$, a higher $\chi$ raises country $h$ 's relative welfare under the currency union case. As discussed also for across-the board changes in the supply slope coefficient $\alpha^{\prime}$, in the event of asymmetric shocks neither inflation nor output is affected by an increasing weight on price stability. Therefore, under this scenario the currency union's relative welfare ratio $C_{u h}$ is determined by developments under monetary autonomy. As usual, welfare loss function $L_{h}$ in (24) rises with a higher $\chi$, which leads to a relative improvement in the monetary union performance. The favorable effect induced by an increase in $\chi$ on monetary union's relative stabilization properties carries over to the cases of aggregate supply shocks of the common and idiosyncratic types.

Figure $5 \mathrm{~b}$ (bottom panel) shows that the impact of higher $\chi$ is detrimental for the currency union under sectoral productivity disturbances, excepting the case of a common shock for which $\tau_{e}=0$. The worsening can be attributed to the standard result that, despite attempts to reduce inflation variability (at the expense of enhanced output volatility), the harsher penalization of inflation's deviations from

${ }^{19}$ The channel involved here is governed by ratio $\phi_{u} / \alpha_{u}$ in the RHS expressions of (37) and (38). This ratio goes down in Case $\mathrm{L}$, implying a more muted contribution of $\kappa_{f}$ to country $h$ 's macroeconomic variability. The opposite is true for Case $\mathrm{H}$. 
Figure 4. Relative Welfare: Sensitivity to $\chi$
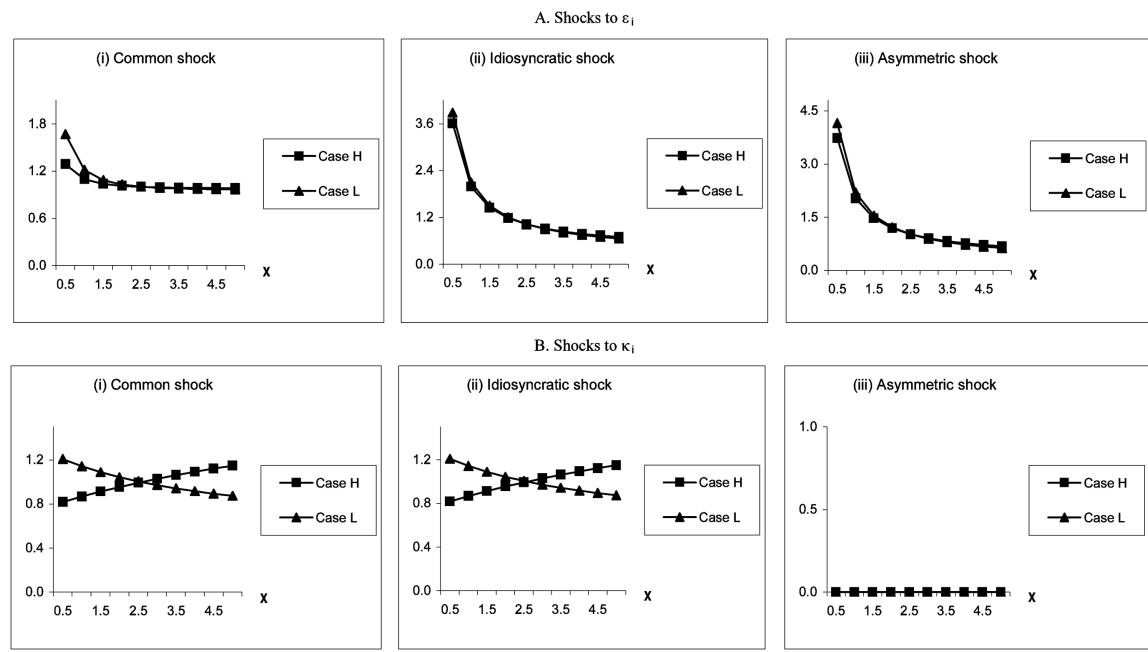

target induces a larger welfare loss.

Again, asymmetric output target disturbances fail to affect monetary union's stabilization performance, which remain superior to the autonomous alternative regime. Under output target shocks of the common and idiosyncratic types, which is the best monetary regime as $\chi$ rises depends on country $h$ 's supply slope type. There is here a tension between monetary policymakers' increased focus on price stability (due to a higher $\chi$ ) and the need to adjust output to the new output

Figure 5a. Reference Country's Welfare Loss Under Sectoral Productivity Shocks: Sensitivity to $\alpha$ and spread
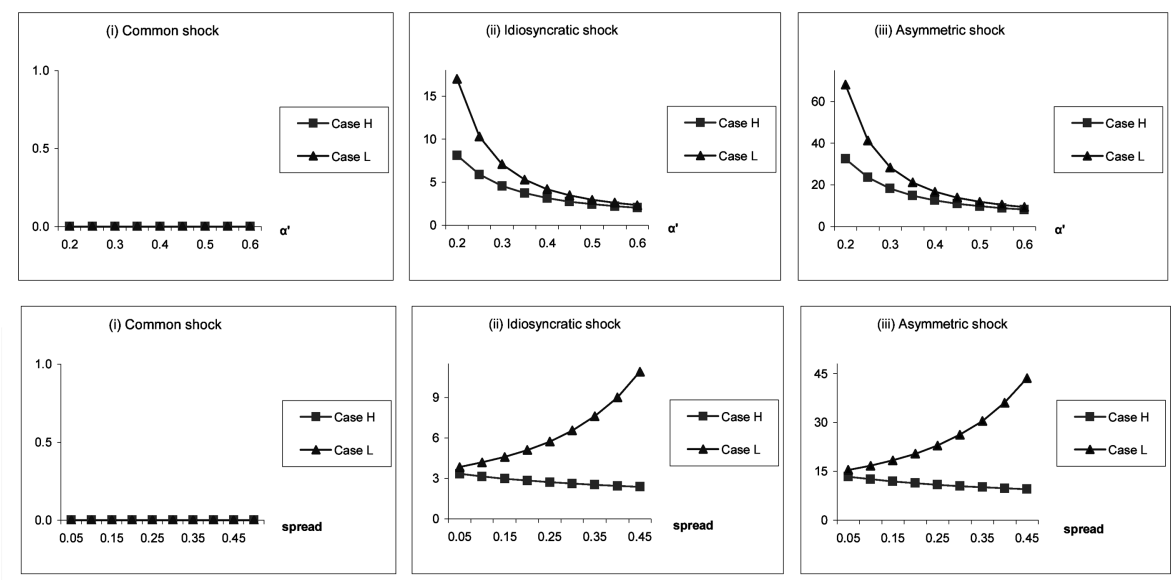
Figure 5b. Reference Country's Welfare Loss under Sectoral Productivity Shocks: Sensitivity to $\varphi$ and $\chi$
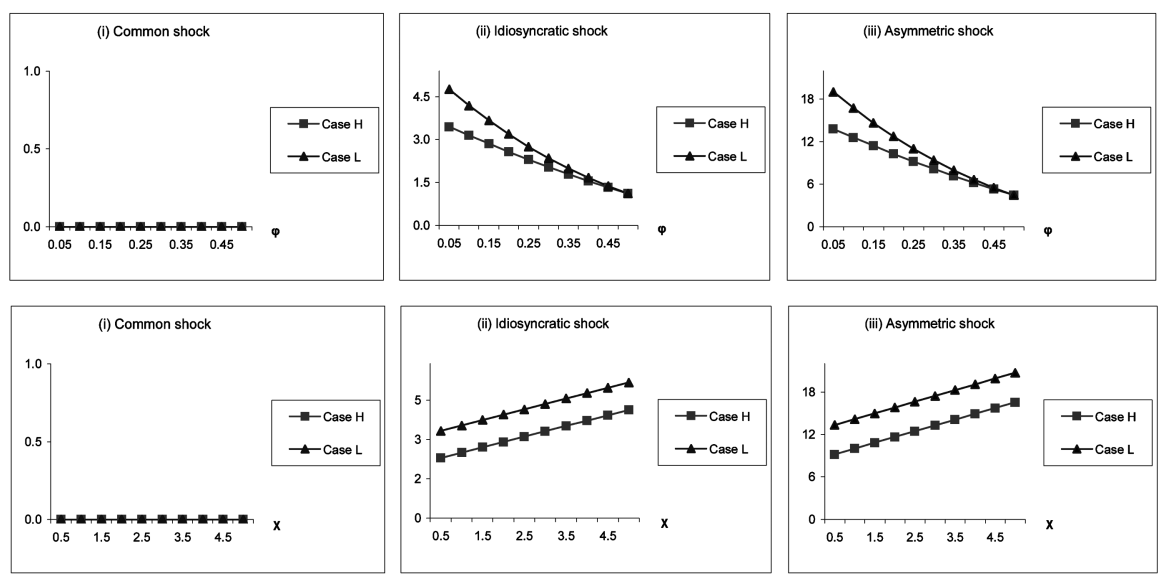

target(s). For reference country of type L, a currency union's stabilization improves because the country, which offers a more favorable tradeoff helping raise output in the new target's direction, is somewhat relieved from this function by the single monetary authority's enhanced concern for inflation variability. In contrast, the same reasoning (now applied to a type-L foreign country) helps understand why a steep-supply reference country $h$ participating in a currency union fails to benefit as much as under autonomy from policy aimed at reducing domestic inflation variability.

\section{Concluding Remarks}

This paper analyzes the implications of extending a currency union model by jointly allowing for catching up features and monetary policy misperceptions. Our empirical study of transparency and growth indicators shows that the economies here considered have exhibited diverse experiences. This is true not only for the countries to first adopt the euro, but also for the candidates that have more recently joined the euro area and those to do so in years to come. Among current euro-area countries (Greece, Ireland, Portugal and Spain) that were catching up with the grouping's more mature economies during the period 1991-1998, this study has detected that considerable differences existed regarding the degree of monetary policy transparency. More concretely, over this period Ireland and Portugal appear to have overperformed the euro area average, while Greece underperformed this 
benchmark and Spain's ranking is found to depend on the specific data source for transparency scores considered. With regard to the remaining relevant catching-up experiences in an EMU environment, one can conclude that EU new member states appear to have been catching up both prior to the euro's launch and thereafter, whereas a number of EU accession countries only exhibited this feature in the latter period. As with current euro-area countries back in the 1990s, the connection between growth and transparency indicators has been affected by both diversity in country experiences and uncertainty about transparency measures obtained from different data sources. This dependence on transparency data sources has been the case more so in the cases of for accession countries and especially EU new member states than for current euro area countries' catching-up process before the launch of the euro. The only result for EU new member states and accession countries that appears to be relatively robust concerns the lower value of transparency scores across the latter grouping's countries vis-à-vis the euro area observed in the mid-2000s.

The relative inconclusiveness surrounding the evidence reported here for the catching-up/transparency nexus suggests that, at the current juncture, the implications of transparency and catching up in monetary union can be better understood by building a general framework that does not impose strong assumptions about the transparency-growth nexus. An effort in developing such general framework, which could then be applied to specific circumstances in further research, is attempted here.

In our model, monetary policy decisions are analysed in an environment of uncertainty about central bank preferences. As in Geraats(2007), we find that optimal monetary policy achieves complete actual and perceived transparency about the inflation target, while for the output target it is beneficial to deliver perfect actual transparency and minimal perceived transparency. This overall combination of transparency about policy targets is found to effectively limit expected inflation volatility, thus making it easier for policymakers to reach their goals. Moreover, optimal policy turns out to imply that output target disturbances play an important role in our welfare analysis, whereas inflation target shocks do not appear to make a difference were a country to renounce monetary sovereignty.

Among all sources of uncertainty considered in this paper, sectoral productivity shocks are the only ones leading to parameter-free welfare implications. These disturbances adversely affect monetary union stabilization properties when they are of the asymmetric or idiosyncratic types (that is, country-specific). As a result, 
monetary autonomy is found to outperform the currency union arrangement under sectoral shocks. This suggests that, in the absence of offsetting factors, catching up countries may fail to benefit from monetary union membership, given that it is unlikely that sectoral shocks would not be synchronized in case member states are at different stages in their development process. For all other shocks, the comparative evaluation of monetary regimes is somewhat more complex, with neither monetary autonomy nor currency union clearly dominating its alternative. It is however worth saying that in all cases (including that of sectoral shocks), our welfare investigation focuses on a sensitivity analysis showing how monetary union stabilization performance is affected by changes in key parameter values.

Our sensitivity analysis proceeded by changing one parameter at a time. However, it is possible to argue that the slope of the Phillips curve is related to country size because both features are in turn linked to trade openness. Indeed, some studies indicate that more open economies also display a flatter supply schedule, while size is often seen as varying inversely with openness. With this in mind, we have sharpened our general analysis for the case of a small open reference country. This type of economy can be characterized as having, on top of a small size, a steep supply schedule in light of the relation between outputinflation tradeoffs and trade openness. A wider gap between national supply curves (as driven by trade openness differentials) is found to unambiguously favor currency union participation of the country facing the steeper supply curve (that is, the more open country). With regard to country size, a small country receives little attention from the single monetary authority, which turns out to be costly in the face of aggregate and sectoral supply disturbances. This partially confirms Sánchez's(2008b) description of the tradeoff facing a small open economy, with small size making a currency union less appealing whereas trade openness lowers relative stabilization costs associated with the single monetary policy. The present paper enriches the analysis by showing that output target disturbances may discourage a bigger country's participation in monetary union, thereby qualifying the advantage of larger size.

\section{Acknowledgements}

We thank valuable comments received from Javier Reyes. The views expressed in this paper are those of the author and need not reflect those of the ECB. The usual disclaimer applies. 
Received 23 May 2008, Revised 23 November 2008, Accepted 27 November 2008

\section{References}

Alesina, A., Spolaore, E.(2003), The Size of Nations, MIT Press, Cambridge MA.

Alesina, A., Spolaore, E., Wacziarg, R.(2005), "Trade, Growth and the Size of Countries", in Handbook of Economic Growth Edited by Aghion, P., Durlauf, S., North Holland, Amsterdam.

Ball, L.(1999), "Policy Rules for Open Economies", in Monetary Policy Rules Edited by Taylor, J., University of Chicago Press, Chicago.

Broadbent, B., Barro, R.(1997), "Central Bank Preferences and Macroeconomic equilibrium", Journal of Monetary Economics, 39, pp 17-43.

Crowe, C., Meade, E.(2008), "Central Bank Independence and Transparency: Evolution and Effectiveness", IMF Working Paper 08/119.

Cukierman, A.(2001), "Accountability, Credibility, Transparency and Stabilization Policy in the Eurosystem", in The Impact of EMU on Europe and the Developing Countries Edited by Wyplosz, C., Oxford University Press, Oxford.

Cukierman, A., Meltzer, A.(1986), “A Theory of Ambiguity, Credibility, and Inflation under Discretion and Asymmetric Information", Econometrica, 54, pp 1099-1128.

Dincer, N., Eichengreen, B.(2007), "Central Bank Transparency: Where, Why, and With What Effects?", NBER Working Paper No. 13003.

Edwards, S.(2006), "Monetary Unions, External Shocks and Economic Performance: a Latin American Perspective", International Economics and Economic Policy, 3, pp 225-247.

Eijffinger, S., Geraats, P.(2006), "How Transparent are Central Banks?", European Journal of Political Economy, 22, pp 1-21.

Eijffinger, S., Hoeberichts, M., Schaling, E.(2000), "Why Money Talks and Wealth Whispers: Monetary Uncertainty and Mystique", Journal of Money, Credit and Banking, 32, pp 218-235.

Faust, J., Svensson, L.(2001), "Transparency and Credibility: Monetary Policy with Unobservable Goals", International Economic Review, 42, pp 369-397.

Faust, J., Svensson, L.(2002), "The equilibrium Degree of Transparency and Control in Monetary Policy", Journal of Money, Credit and Banking, 34, pp 520-539.

Frankel, J., Rose, A.(1998), "The Endogeneity of the Optimum Currency Area Criteria", Economic Journal, 108, pp 1009-1025.

Fry, M., Julius, D., Mahadeva, L., Roger, S., Sternen, G.(2000), "Key Issues in the Choice of Monetary Policy Framework", in Monetary Policy Frameworks in a Global Context Edited by Mahadeva, L., Sterne, G., Routledge, London.

Geraats, P.(2007), "The Mystique of Central Bank Speak", International Journal of Central Banking, 1, pp 37-80. 
Hahn, V.(2006), "The Transparency of Central Bank Preferences", Mimeo [Online], Swiss Federal Institute of Technology. Available at http://ssrn.com/abstract=592261.

Kalemli-Ozcan, S., Sørensen, B., Yosha, O.(2001), "Economic Integration, Industrial Specialization, and the Asymmetry of Macroeconomic Fluctuations", Journal of International Economics, 55, 107-137.

Lane, P.(2000), "Asymmetric Shocks and Monetary Policy in a Currency Union", Scandinavian Journal of Economics, 102, 585-604.

Morris, S., Shin, H.(2002), "Social Value of Public Information", American Economic Review, 92, 1521-1234.

Romer, D.(1993), "Openness and Inflation: Theory and Evidence", Quarterly Journal of Economics, 108, 869-903.

Sánchez, M.(2006), "Is Time Ripe for a Currency Union in Emerging East Asia?: the Role of Monetary Stabilisation", Journal of Economic Integration, 21, 736-763.

Sánchez, M.(2007a), "Monetary Stabilisation in a Currency Union: The Role of Catching up member states", Journal of Policy Modeling, 29, 29-40.

Sánchez, M.(2007b), "How Does Information Affect the Comovement Between Interest Rates and Exchange Rates?", Rivista Internazionale di Scienze Sociali, 2007/4, 547562.

Sánchez, M.(2008a), “The Link between Interest Rates and Exchange Rates: Do Contractionary Depreciations Make a Difference?", International Economic Journal, 22, 43-61.

Sánchez, M.(2008b), "Implications of Monetary Union for Catching-up Member States", Open Economies Review, 19, 371-390.

Sánchez, M.(2008c), "Monetary Stabilisation in a Currency Union of Small Open Economies", ECB Working Paper No 927.

Sørensen, J.(1991), "Political Uncertainty and Macroeconomic Performance", Economics Letters, 37, 377-381.

Walsh, C.(2007), “Optimal Economic Transparency", International Journal of Central Banking, 1, 5-36. 